\title{
Glucose and Insulin Stimulate Lipogenesis in Porcine Adipocytes: Dissimilar and Identical Regulation Pathway for Key Transcription Factors
}

\author{
Zhang Guo Hua ${ }^{1}$, Lu Jian Xiong ${ }^{1, *}$, Chen Yan ${ }^{1}$, Dai Hong Wei ${ }^{1}$, ZhaXi YingPai ${ }^{1}$, Zhao Yong Qing ${ }^{1}$, \\ Qiao Zi Lin ${ }^{2}$, Feng Ruo Fei ${ }^{2}$, Wang Ya Ling ${ }^{1}$, and Ma Zhong Ren ${ }^{2, *}$
}

\begin{abstract}
Lipogenesis is under the concerted action of ChREBP, SREBP-1c and other transcription factors in response to glucose and insulin. The isolated porcine preadipocytes were differentiated into mature adipocytes to investigate the roles and interrelation of these transcription factors in the context of glucose- and insulin-induced lipogenesis in pigs. In ChREBP-silenced adipocytes, glucose-induced lipogenesis decreased by $\sim 70 \%$, however insulin-induced lipogenesis was unaffected. Moreover, insulin had no effect on ChREBP expression of unperturbed adipocytes irrespective of glucose concentration, suggesting ChREBP mediate glucose-induced lipogenesis. Insulin stimulated SREBP-1c expression and when SREBP-1c activation was blocked, and the insulin-induced lipogenesis decreased by $\sim 55 \%$, suggesting SREBP-1c is a key transcription factor mediating insulin-induced lipogenesis. LXR $\alpha$ activation promoted lipogenesis and lipogenic genes expression. In ChREBPsilenced or SREBP-1c activation blocked adipocytes, LXR $\alpha$ activation facilitated lipogenesis and SREBP-1c expression, but had no effect on ChREBP expression. Therefore, LXR $\alpha$ might mediate lipogenesis via SREBP-1c rather than ChREBP. When ChREBP expression was silenced and SREBP-1c activation blocked simultaneously, glucose and insulin were still able to stimulated lipogenesis and lipogenic genes expression, and $L X R \alpha$ activation enhanced these effects, suggesting $L X R \alpha$ mediated directly glucoseand insulin-induced lipogenesis. In summary, glucose and insulin stimulated lipogenesis through both dissimilar and identical regulation pathway in porcine adipocytes.
\end{abstract}

\section{INTRODUCTION}

Adipose tissue is an organ which is responsible for energy

\footnotetext{
${ }^{1}$ College of Life Science and Engineering, ${ }^{2}$ Gansu Engineering Research Center for Animal Cell, Northwest University for Nationalities, Lanzhou, Gansu 730030, China

*Correspondence: smljx@xbmu.edu.cn (LJX); mzr651207@163.com (MZR)

Received 7 July, 2016; revised 4 October, 2016; accepted 20 October, 2016; published online 18 November, 2016
}

Keywords: ChREBP, LXR $\alpha$, lipogenesis, porcine adipocytes, SREBP-1c storage in the form of lipids and, in pigs, is responsible for the conversion of excess dietary carbohydrates into triglycerides (TG). It is one of the major pathways of lipogenesis, using glucose as substrate for de nove lipogenesis, which is critically important for mammals that utilize carbohydrates as the major energy source. Pig adipose tissue is the main lipogenesis organ (Bergen et al., 2005) and has a greater contribution to overall FA synthesis than the liver (O'Hea and Leveille, 1969). Fatty acid synthesis is a complex process which involves numerous enzymes and signaling proteins. Induction of lipogenic genes (such as acetyl-CoA carboxylase 1, ACC1, and fatty acid synthase, FAS) is under the concerted action of the transcription factor carbohydrate response element binding protein (ChREBP) and of sterol regulatory element-binding protein 1c (SREBP-1c), which respond to glucose and insulin, respectively (Dentin et al., 2005; Uyeda et al., 2006; Xu et al., 2013). Researches have suggested that Liver $X$ receptors $\alpha(L X R \alpha)$ may play a central role in the transcriptional control of ChREBP by glucose (Cha and Repa, 2007) and SREBP-1c by insulin (Chen et al., 2004; 2007; Schultz et al., 2000). Both ChREBP and SREBP-1c gene have been identified as targets of LXRs (Cha and Repa, 2007; Repa et al., 2000). LXRs may play a crucial role in the regulation of energy homeostasis in adipocytes and be a potential target for the treatment of obesity and energy regulation (Janowski et al., 1999; Korach-Andre et al., 2011; Lehmann et al., 1997).

Despite the recent rapidly expanding knowledge base regarding the role of ChREBP and SREBP-1c in the liver, it remains unclear whether there is interrelation between the lipogenesis induced by glucose and by insulin, and whether $\mathrm{LXR} \alpha$ is involved in lipogenesis induced by glucose or insulin in adipocytes. Moreover, studies evaluating ChREBP and SREBP$1 \mathrm{c}$ regulations have been always addressed in rodent models or human cell lines, but never in pigs. Pigs are among one of the animals with greatest fat deposit capacity, and the deposition and distribution of fat affect the carcass quality and meat flavor. Thus, understanding the mechanism of lipogenesis in adipocytes, highly specialized cells that consist of the main part of the adipose tissue, is not only an interesting biomedical model for human diseases, but also relevant for the improvement of pork quality (Dodson et al., 2010).

In this study, primary cultured porcine adipocytes were used to investigate the roles and interrelation of key transcription factors $L X R \alpha$, ChREBP and SREBP-1c in mediating glucoseand insulin-induced lipogenesis. We demonstrated that glucose 
stimulates lipogenesis and expression of lipogenic-related genes independently of insulin in porcine adipocytes, but insulin promotes lipogenesis only in the presence of glucose. Lipogenesis induced by glucose and by insulin were mediated by ChREBP and SREBP-1c, respectively. However, LXR $\alpha$ mediated glucose- and insulin-induced lipogenesis either directly or via SREBP-1c. Therefore, glucose and insulin could stimulate lipogenesis through both dissimilar and identical regulation pathway in porcine differentiated adipocytes.

\section{MATERIALS AND METHODS}

\section{Experimental animals}

Three-day-old male crossbred piglets (Duroc $\times$ Landrace $\times$ Large White) from different litters were used in this study. The piglets were provided by Zai-wang pig farm of Gansu Yuzhong. Experiments were conducted in accordance with "The Instructive Notions with Respect to Caring for Laboratory Animals" issued by the Ministry of Science and Technology of the People's Republic of China.

\section{Cell culture and treatments}

Primary cultures of preadipocytes were isolated as previously described (Zhang et al., 2014). Cells were seeded in 25-cm culture flask and maintained in basal medium, DMEM/F12 medium (GIBCO/BRL, USA) supplemented $10 \%$ fetal bovine serum (FBS, ScienCell, USA), at $37^{\circ} \mathrm{C}$ in humidified atmosphere with $5 \% \mathrm{CO}_{2}$. Five days after reaching confluence, cells were digested and re-seeded in 24-cell plates. Cells grown to confluence were exposed to the adipogenic medium, the basal medium containing $100 \mathrm{nmol} / \mathrm{L}$ insulin (Sigma-Aldrich), $1 \mu \mathrm{mol} / \mathrm{L}$ dexamethasone (Sigma-Aldrich) and $0.5 \mathrm{mmol} / \mathrm{L}$ IBMX (SigmaAldrich) for 3 days, followed by culturing for an additional 3 days in a basal medium containing $100 \mathrm{nmol} / \mathrm{L}$ insulin. The cells were then grown for an additional 6 days in basal medium to ensure that all cells had become differentiated adipocytes (d12). To investigate the effect of glucose on lipogenesis in adipocytes, well-differentiated adipocytes were placed in glucose-free DMEM medium for $24 \mathrm{~h}$, and then transferred to the basal DMEM medium containing 0-25 mmol/L D-glucose (SigmaAldrich). For the insulin stimulation experiment, differentiated adipocytes were cultured for $12 \mathrm{~h}$ in serum-free medium containing either 0 or $25 \mathrm{mmol} / \mathrm{L}$ glucose, and the $0-400 \mathrm{nmol} / \mathrm{L}$ insulin was added into the culture medium. The related information of treatment sequence was described in detail in the legend.

SiRNA for ChREBP and SREBP-1c blocked by fatostatin ChREBP expression was knocked down by pcDNA ${ }^{\mathrm{TM} 6.2-}$ GW/EmGFP-ChREBP. Detailed information regarding siRNA targeting ChREBP has been described previously (Zhang et al., 2015). Differentiated adipocytes were incubated using the siRNA/ Lipofectamine complex in serum-free medium for $6 \mathrm{~h}$ and then switched to a basal medium for $48 \mathrm{~h}$.

The activation of SREBP-1c was blocked using the inhibitor fatostatin $(10 \mu \mathrm{mol} / \mathrm{L})$ (Sigma, USA). After $24 \mathrm{~h}$, cells were lysed and the protein concentration was determined using the method of Lin et al (2007). Equal amounts of protein were analyzed by Western blotting using antibodies specific for SREBP1c (USA) and $\beta$-actin (USA).

ChREBP-siRNA cells and SREBP-1c blocked cells were cultured in glucose-free and/or serum-free DMEM medium and subsequently cultured in the absence or presence of glucose (20 $\mathrm{mmol} / \mathrm{L}$ ) with 0 or $200 \mathrm{nmol} / \mathrm{L}$ insulin, as indicated in the figure legends. Sodium pyruvate $(2 \mathrm{mmol} / \mathrm{L})$ (Sigma-Aldrich) was added to the medium to replace glucose as carbon source when cells were cultured in glucose-free medium. T0901317 (1 $\mu \mathrm{mol} / \mathrm{L}$ ) (Sigma) was used as agonist to promote the activation of $L X R \alpha$. These concentrations were chosen base on initial dose-response experiments (data not shown).

\section{Cellular lipid content analysis}

The cellular lipid content analysis was performed using Oil Red O staining extraction assay as described by Ramírez-Zacarías et al. (1992). In brief, cells were cultured in 24-cell plates and rinsed twice with $\mathrm{Ca}^{2+}$ and $\mathrm{Mg}^{2+}$-free PBS, then fixed in $10 \%$ neutralized formalin at least for $1 \mathrm{~h}$. Cells were stained for $2 \mathrm{~h}$ by complete immersion in $0.2 \%$ Oil Red O (Sigma-Aldrich) prepared in $60 \%$ isopropanol solution followed by multiple rinses with water. Cell morphology was examined and photographed with a microscope. The stained culture dishes were subjected to dye extraction with isopropanol. The optical density (OD) of the solution was measured at $510 \mathrm{~nm}$ for quantification, using a UV-2102 PC ultraviolet spectrophotometer (Unico Instrument Co., Ltd., China).

\section{Quantitative PCR Analysis}

Total cellular RNA was extracted using TRIzol reagent using standard techniques (Gibco/BRL, USA). Real time RT-PCR was performed using a Superscript RT III enzyme kit from Invitrogen (USA). SYBR Green was used as the detection reagent for quantification using the $2^{\triangle \triangle C T}$ method and $\beta$-actin expression of a control CDNA was used as an inter-plate calibrator. The specificity of the PCR amplification was evaluated using a melting curve analysis. Table 1 provided details of primers of the genes studied.

\section{Statistical analysis}

Data is presented as mean \pm SEM. All data were obtained from experiments carried out in triplicate. Data were analyzed by ANOVA using SPSS version 17.0 software (SPSS science, USA). Duncan's multiple range tests was used for statistical comparisons. $P<0.05$ or $P<0.01$ were regarded as statistically significant.

\section{RESULTS}

\section{Morphological observations of adipocytes}

The isolated cells were seeded in DMEM/F12 medium supplemented $10 \%$ fetal bovine serum. The preadipocytes attached and spread around $24 \mathrm{~h}$ after seeding (Supplementary Fig. 1A). Exponentially growing porcine preadipocytes (3-7 days) exhibited a fibroblastic appearance (Supplementary Fig. 1B), and differentiation of adipocytes was initiated by treating confluent preadipocytes (Supplementary Fig. 1C) with the adipogenic medium (d 0). Five days after stimulation, the lipid-filled cells increased distinctly (Supplementary Fig. 1D) and the lipid-filled cells could be dyed by Oil Red O staining (Supplementary Fig. 1E). The lipid-filled cells increased with the induction time extension (Supplementary Fig. 1F).

Glucose and insulin induced lipogenesis in differentiated adipocytes

To study the effects of glucose and insulin on lipogenesis in porcine mature adipocytes, isolated preadipocytes were induced to differentiate into adipocytes and treated by glucose and insulin, respectively. As shown in Fig. 1A, glucose at concentrations of 5 to $20 \mathrm{mmol} / \mathrm{L}$ promoted lipogenesis in a dose- 
Table 1. The Primers of real-time PCR

\begin{tabular}{|c|c|c|c|c|}
\hline Gene* $^{*}$ & Accession No. & Primer sequence $\left(5^{\prime}-3^{\prime}\right)$ & Length, bp & Product size, bp \\
\hline \multirow[t]{2}{*}{ ChREBP } & DQ372586.1 & F: GTATGTGGAGCGGAGGAAGAG & 21 & 93 \\
\hline & & R: ATGACGGCCTCGGGTTT & 17 & \\
\hline \multirow[t]{2}{*}{ SREBP-1c } & AY307771.1 & F: TGAAGCCGGAGGTGGTAGA & 19 & 161 \\
\hline & & R: CTTCATCTGGCTGTCCTCAAAA & 22 & \\
\hline \multirow[t]{2}{*}{$\mathrm{LXR} \alpha$} & AB254406 & F:CTCGGACAGTCCCTTGGTAA & 20 & 85 \\
\hline & & R: TCAGGAGAAACATCAGGCACA & 21 & \\
\hline \multirow[t]{2}{*}{ FAS } & EF589048.1 & F: AAGCAGGCGAACACGATG & 18 & 94 \\
\hline & & R: GAAGGGAAGCAGGGTTGATG & 20 & \\
\hline \multirow[t]{2}{*}{ ACC1 } & EU168399 & R: AAGGGCTGCCTCTAATG & 17 & 95 \\
\hline & & R: GATGTAAGCGCCGAACT & 17 & \\
\hline \multirow[t]{2}{*}{$\beta$-actin } & AF054837 & F: GATCGTGCGGGACATCAA & 18 & 180 \\
\hline & & R: AGGAAGGAGGGCTGGAAGAG & 20 & \\
\hline
\end{tabular}

${ }^{*}$ ChREBP = Carbohydrate response element-binding protein; SREBP-1c = Sterol regulatory element-binding protein-1c; $L X R \alpha=$ liver X receptor alpha; FAS = Fatty acid synthase; $A C C 1=$ acetyl coenzyme A carboxylase 1

A

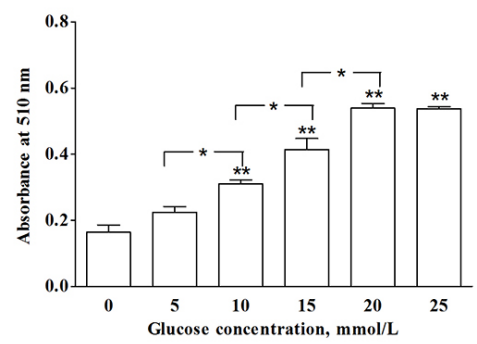

B $\square 0 \mathrm{mmol} / \mathrm{L}$ glucose $\square 20 \mathrm{mmol} / \mathrm{L}$ glucose

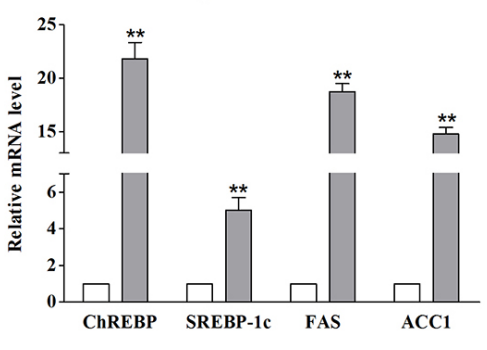

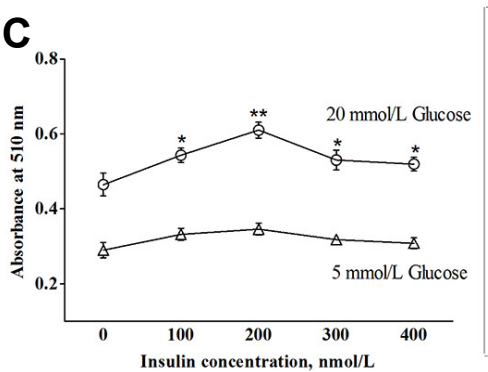

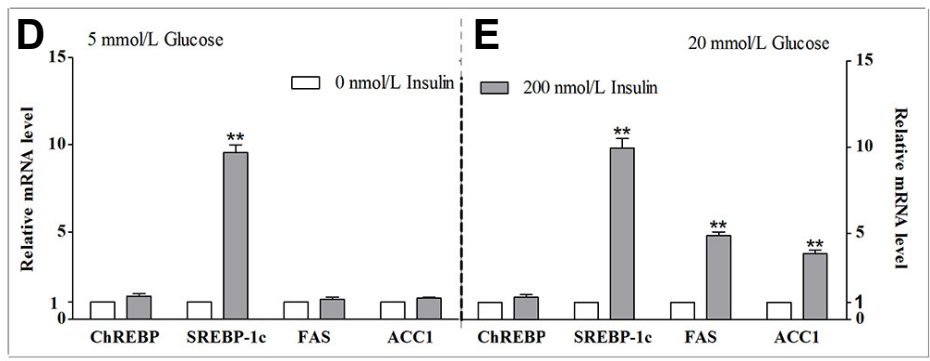

Fig. 1. Lipogenesis and relative gene expression induced by glucose and insulin in porcine adipocytes. (A, B) Fully differentiated porcine adipocytes were cultured in a glucose-free medium for $24 \mathrm{~h}$, and then shifted to the medium with different concentrations glucose (mmol/L) for 24 $\mathrm{h}$. The effect of different glucose concentration $(\mathrm{mmol} / \mathrm{L})$ on lipogenesis $(\mathrm{A})$. The relative genes expression induced by 0 (open bars) or 20 $\mathrm{mmol} / \mathrm{L}$ glucose (grey bars) (B). (C, D, and E) Fully differentiated porcine adipocytes were cultured in a serum-free medium for $12 \mathrm{~h}$, and shifted to the medium with variable concentrations of insulin ( $\mathrm{nmol} / \mathrm{L}$ ) for $24 \mathrm{~h}$. Quantification of lipogenesis in differentiated adipocytes by Oil Red $\mathrm{O}$ extraction (C) and the relative gene expressions induced by 0 (open bars) or $200 \mathrm{nmol} / \mathrm{L}$ insulin (grey bars) in the presence of 5 (D) or 20 $\mathrm{mmol} / \mathrm{L}$ glucose $(\mathrm{E}) .{ }^{*}(P<0.05)$ and ${ }^{* *}(P<0.01)$ meant the significant for the treatment compared to $0 \mathrm{nmol} / \mathrm{L}$ insulin. Data are means $\pm \mathrm{SEM}$

dependent manner $(P<0.05)$. However, $5 \mathrm{mmol} / \mathrm{L}$ glucose did not lead to a noticeable increase in lipogenesis $(P>0.05)$. Moreover, the stimulatory effect of glucose was not different between $25 \mathrm{mmol} / \mathrm{L}$ and $20 \mathrm{mmol} / \mathrm{L}(P>0.05)$. As such, the effect of $20 \mathrm{mmol} / \mathrm{L}$ glucose on the mRNA expressions of transcription factor (ChREBP and SREBP-1c) and lipogenic genes (FAS and ACC1) were analyzed (Fig. 1B). Glucose (20 $\mathrm{mmol} / \mathrm{L}$ ) significantly induced the expression of ChREBP and lipogenic genes FAS and ACC1 $(P<0.01)$. Glucose also stimulated SREBP-1c mRNA expression $(P<0.01)$, to a lesser extent.
In $5 \mathrm{mmol} / \mathrm{L}$ glucose condition, no change was seen in lipogenesis when the differentiated porcine adipocytes were treated with different concentration of insulin. However in $20 \mathrm{mmol} / \mathrm{L}$ glucose condition, insulin significantly promoted the lipogenesis $(P<0.05)$, and lipogenesis reached maxima at $200 \mathrm{nmol} / \mathrm{L}$ insulin $(P<0.01)$ (Fig. 1C). When treated with $200 \mathrm{nmol} / \mathrm{L}$ insulin, noticeable increases in FAS and ACC1 mRNA were observed in the cells cultured in high glucose condition instead of in low glucose condition (Figs. 1D and 1E). Insulin promoted increased expression of SREBP-1c mRNA levels independently of surrounding glucose concentration $(P<0.01)$. However, 

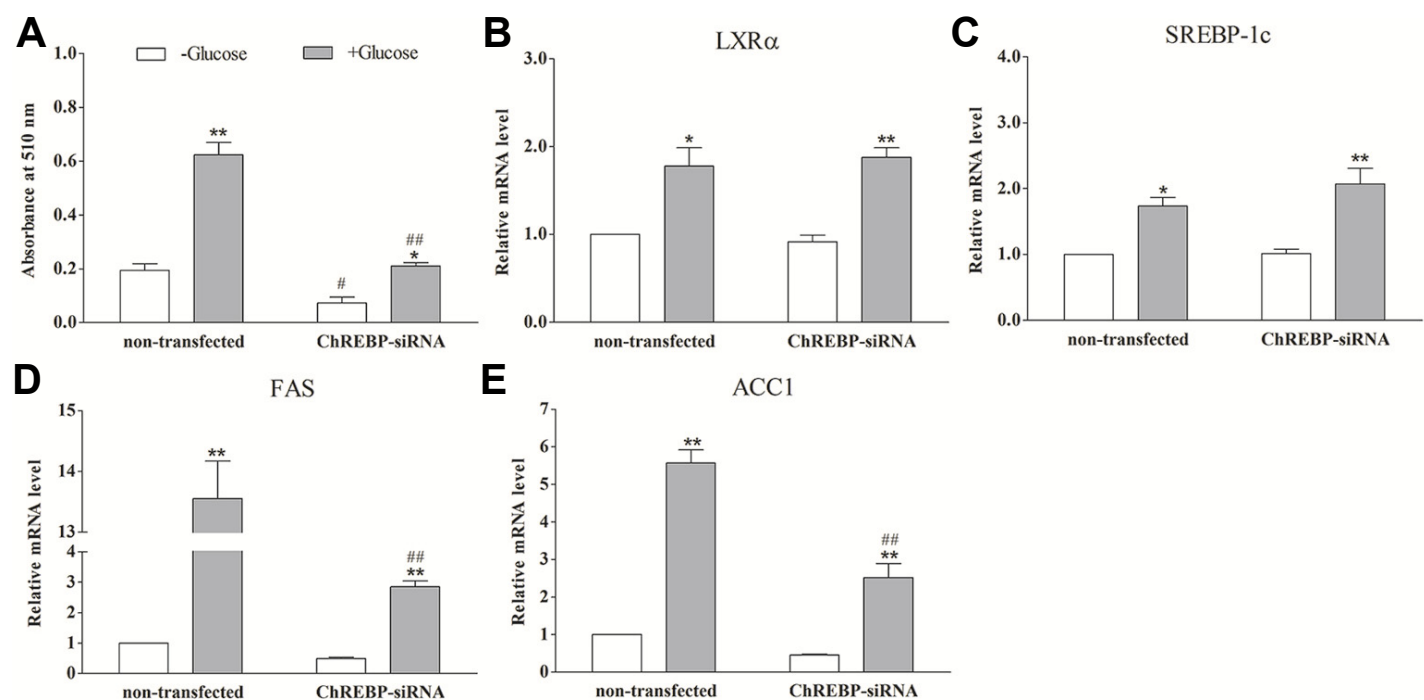

Fig. 2. The effect of glucose on lipogenesis and relative gene expression in ChREBP-silenced porcine adipocytes. The ChREBP-siRNA and non-transfected adipocytes were shifted to glucose-free medium for $24 \mathrm{~h}$ and subsequently transferred to basal medium with 0 (open bars) or $20 \mathrm{mmol} / \mathrm{L}$ glucose (grey bars). After $24 \mathrm{~h}$, lipogenesis and mRNA levels of specific genes were evaluated. ChREBP-siRNA means the cells transfected with pcDNA6.2-GW/EmGFP-ChREBP siRNA expression plasmid. Non-transfected indicates the unperturbed adipocytes. ${ }^{*}(P<$ $0.05)$ and ${ }^{* *}(P<0.01)$ mean the significant between treatments in the same cell group. ${ }^{\#}(P<0.05)$ and ${ }^{\# \#}(P<0.01)$ mean the significant between the same treatment in different cell groups. (A) Quantification of lipogenesis in differentiated adipocytes by Oil Red O extraction. (B-E) The relative mRNA level of $L X R \alpha(B)$, SREBP-1c (C), FAS (D) and ACC1 (E) measured by using real-time RT-PCR. Data are means \pm SEM.

insulin was unable to facilitate the expression of ChREBP at 5 or $20 \mathrm{mmol} / \mathrm{L}$ glucose (Figs. 1D and $1 \mathrm{E}$ ). These results suggest that in porcine differentiated adipocytes, glucose and insulin promote the lipogenesis and lipogenic gene FAS and ACC1 mRNA level. More specifically, insulin facilitated lipogenesis and the mRNA expression of lipogenic genes (FAS and ACC1) in a glucose-dependent mechanism.

\section{ChREBP siRNA transfection to the differentiated porcine adipocytes}

pcDNA6.2-GW/EmGFP-ChREBP siRNA was transfected to differentiated porcine adipocytes to inhibit the gene expression of ChREBP, and the transfection efficiency was examined using fluorescence microscope after $48 \mathrm{~h}$ (Supplementary Fig. $2 A)$. The total RNA was extracted and the relative mRNA expression of ChREBP was tested by real time PCR. The ChREBP gene expression decreased by around $80 \%$ in ChREBP siRNA transfected adipocytes. Compared to the unperturbed cells, ChREBP gene expression was not affected in the cells transfected with negative siRNA (Supplementary Fig. $2 \mathrm{~B}$ ). These results indicated that the expression of ChREBP was inhibited successfully by the transfection of pcDNA6.2GW/EmGFP-ChREBP siRNA in the porcine adipocytes.

ChREBP mediated mainly glucose-induced lipogenesis in differentiated adipocytes

To investigate the potential roles of ChREBP in glucoseinduced lipogenesis, adipocytes with siRNA-mediated ChREBP knockdown were placed in glucose-free for $24 \mathrm{~h}$, and transferred to the medium with 0 or $20 \mathrm{mmol} / \mathrm{L}$ glucose. Sodium pyruvate $(2 \mathrm{mmol} / \mathrm{L})$ was added as carbon source in glucosefree medium. ChREBP gene expression were similar between non-transfected and negative siRNA adipocytes (Supplementary Fig. 2B), therefore the non-transfected cells were used as control cells.

After $24 \mathrm{~h}$, lipogenesis significantly increased both in nontransfected $(P<0.01)$ and ChREBP silenced cells $(P<0.05)$ in response to $20 \mathrm{mmol} / \mathrm{L}$ glucose. However, glucose-induced lipogenesis was reduced by $\sim 70 \%$ when ChREBP gene expression was silenced $(P<0.01)$ (Fig. 2A). Although the mRNA expression of lipogenic genes FAS (Fig. 2D) and ACC1 (Fig. 2E) were significantly promoted by glucose in ChREBP silenced adipocytes $(P<0.01)$, it was much lower than levels observed in non-transfected cells $(P<0.01)$. The glucoseinduced up-regulations of LXR $\alpha$ and SREBP-1c mRNA expression were observed both in non-transfected $(P<0.05)$ and ChREBP silenced adipocytes $(P<0.01)$, and loss of ChREBP seemed to have no effect on their mRNA expressions $(P>$ 0.05 ) (Figs. $2 \mathrm{~B}$ and $2 \mathrm{C}$ ). These data suggest that ChREBP is a critical mediator in glucose-induced lipogenesis, while $\operatorname{LXR} \alpha$ and SREBP-1c might also play a contributing role.

Due to no distinct effects of insulin on lipogenesis under low glucose concentration, ChREBP-siRNA adipocytes were treated with $200 \mathrm{nmol} / \mathrm{L}$ insulin in the presence of $20 \mathrm{mmol} / \mathrm{L}$ glucose to investigate the potential role of ChREBP in insulininduced lipogenesis. From the Fig. 3, though lipogenesis significantly decreased from baseline when ChREBP expression was silenced $(P<0.01)$, the addition of insulin still led to a marked increase in lipogenesis $(P<0.01)$. Moreover, there was no difference in the extent of lipogenic induction promoted by insulin between both cell groups $(0.136$ vs. 0.132$)(P>0.05)$ (Fig. 3A). As expected with the induction of lipogenesis, mRNA levels of FAS and ACC1 was significantly promoted by insulin both in non-transfected and ChREBP-siRNA adipocytes $(P<$ 0.01 ) (Figs. $3 D$ and $3 E$ ). Insulin significantly facilitated the SREBP-1C and LXR $\alpha$ expression in both conditions. Furthermore, SREBP-1c mRNA levels promoted by insulin were higher in ChREBP-siRNA adipocytes than that in non-transfected 

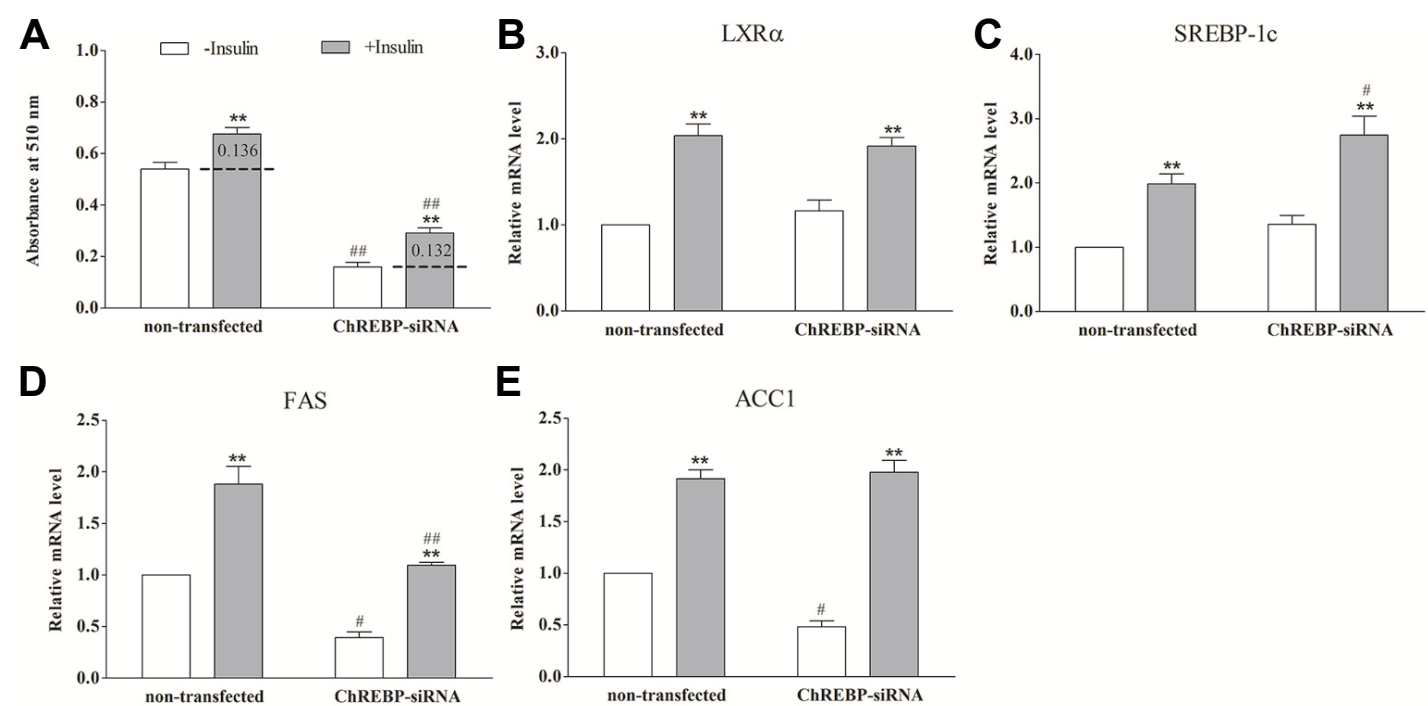

Fig. 3. The effect of insulin on lipogenesis and genes expression in ChREBP-siRNA porcine differentiated adipocytes. The ChREBP-siRNA and non-transfected adipocytes were shifted to serum-free medium for $12 \mathrm{~h}$ and transferred to basal medium containing $20 \mathrm{mmol} / \mathrm{L}$ glucose in the absence (open bars) or presence (grey bars) of $200 \mathrm{nmol} / \mathrm{L}$ insulin for $24 \mathrm{~h}$. Lipogenesis and mRNA of specific genes were evaluated. ChREBP-siRNA means the cells transfected with pcDNA6.2-GW/EmGFP-ChREBP siRNA expression plasmid. Non-transfected indicates the unperturbed adipocytes. ${ }^{*}(P<0.05)$ and ${ }^{* *}(P<0.01)$ mean the significant between treatments in the same cell group. ${ }^{\#}(P<0.05)$ and ${ }^{\# \#}(P<$ $0.01)$ mean the significant between the same treatment in different cell groups. A: Quantification of lipogenesis in differentiated adipocytes by Oil Red O extraction. B-E: The relative mRNA level of $L X R \alpha(B)$, SREBP-1c (C), FAS (D) and ACC1 (E) measured by using real-time RT-PCR. Data are means \pm SEM.

cells $(P<0.05)$ (Fig. 3C). ChREBP expression silencing had no effect on the mRNA level of $L X R \alpha$ when the adipocytes were treated with $200 \mathrm{nmol} / \mathrm{L}$ insulin (Fig. 3B). These results suggested that silencing ChREBP does not attenuate the lipogenic affects of insulin in porcine differentiated adipocytes, and that insulin has no effect on the ChREBP expression in the absence or presence of glucose. Taken together, these results suggest that insulin does not induce lipogenesis through ChREBP.

SREBP-1c mediated mainly insulin-induced lipogenesis in differentiated adipocytes

To assess the potential roles of SREBP-1c in lipogenesis facilitated by insulin, SREBP-1c activation was blocked markedly ( $P$ $<0.01$ ) using the inhibitor fatostatin (Supplementary Fig. 3). As an inhibitor of the SREBP activation, fatostatin impairs the activation process of SREBP-1c, thereby decreasing the transcription of lipogenic genes in cells (Kamisuki et al., 2009; Uttarwar et al., 2012). Differentiated adipocytes were cultured in serumfree medium for $12 \mathrm{~h}$, and then transferred to the basal medium containing $20 \mathrm{mmol} / \mathrm{L}$ glucose in the absence or presence of insulin $(200 \mathrm{nmol} / \mathrm{L})$. Meanwhile, $10 \mu \mathrm{mol} / \mathrm{L}$ fatostatin was added in the medium for blocking the activation of SREBP-1c. After $24 \mathrm{~h}$, the cellular lipid content and related genes expression were evaluated.

There was a marked stimulation of insulin on lipogenesis in differentiated adipocytes $(P<0.01)$. When the adipocytes were treated with SREBP-1c inhibitor fatostatin, however, the lipogenesis was decreased by $\sim 55 \%$ (Fig. 4). Despite pharmacological suppression of SREBP-1c via fatostatin, addition of insulin still led to a significant increase in lipogenesis $(P<0.01)$, however the magnitude of the stimulation was much lower than that of the untreated cells $(0.102$ vs. 0.220$)(P<0.01)$ (Fig. 4A). The lipogenic genes FAS and ACC1 expression were promot- ed by insulin both in adipocytes untreated and treated with fatostatin, however, inhibition of SREBP-1c attenuated FAS and ACC1 gene expression ( $P<0.01$ ) (Figs. 4D and 4E). ChREBP mRNA expression was not affected by $200 \mathrm{nmol} / \mathrm{L}$ insulin irrespective of whether the cells were treated with fatostatin or not $(P<0.01)$ (Fig. $4 \mathrm{C})$. There was a profound increase in $L X R \alpha$ expression both in fatostatin-treated and untreated adipocytes in response to insulin $(P<0.05)$, and there was no difference between the cell groups (Fig. 4B). These data suggest that SREBP-1c is a key transcription factor in insulin-induced lipogenesis, while LXR $\alpha$ participate in this response.

LXR $\alpha$ activation promoted the lipogenesis in adipocytes To study whether $L X R \alpha$ is involved in the lipogenesis induced by glucose and insulin, T0901317 was used to activate LXR $\alpha$ in ChREBP-silenced and separately, fatostatin-treated adipocytes. T0901317 (N-(2,2,2-trifluoroethyl)-N-[4-(2,2,2-trifluoro- 1-hydroxy1-trifluorome thylethyl) phenyl]-benzene-sulfona mide) is $\mathrm{LXR} \alpha$ agonist which could increase the activation of $L X R \alpha$ (Schultz et al., 2000; Zanotti et al., 2008). Adipocytes were cultured in the basal medium containing $20 \mathrm{mmol} / \mathrm{L}$ glucose with or without T0901317 (1 $\mu \mathrm{mol} / \mathrm{L})$ for $24 \mathrm{~h}$, and then the cellular lipid content and the lipogenic gene expression were measured.

In porcine differentiated adipocytes, activation of $L X R \alpha$ by T0901317 significantly promoted the lipogenesis and lipogenic gene expression (FAS and ACC1) (Fig. 5). Although lipogenesis decreased by $\sim 70 \%$ when ChREBP expression was silenced (as compared to the control cells), lipogenesis could still be increased using the LXR $\alpha$ agonist $(P<0.05)$ (Fig. 6A). In SREBP-1c blocked adipocytes, lipogenesis was decreased by $\sim 55 \%$, while $\mathrm{LXR} \alpha$ activation resulted in only a trend towards increased lipogenesis $(P>0.05)$ (Fig. 6A). T0901317 also in- 

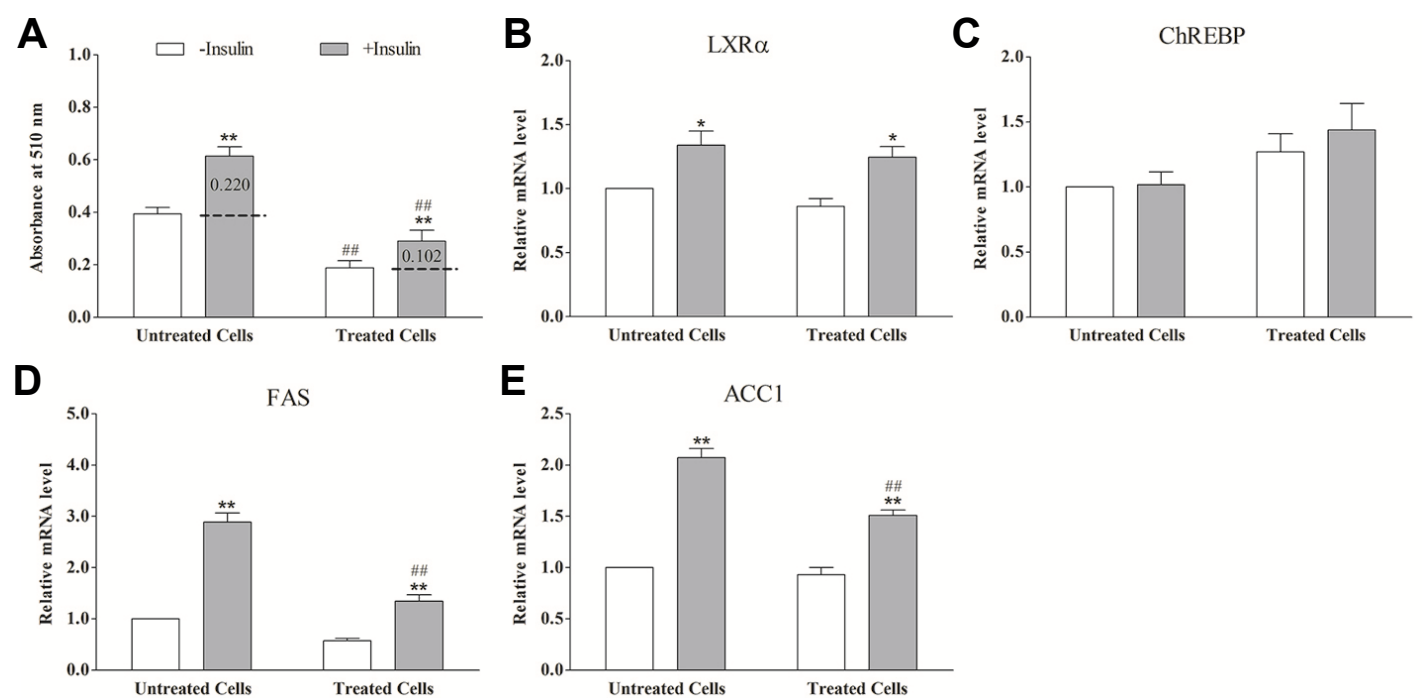

Fig. 4. The effect of insulin on lipogenesis and genes expression in SREBP-1c blocked adipocytes. Differentiated adipocytes were shifted to a serum-free medium containing $5 \%$ bovine serum albumin for $12 \mathrm{~h}$, and then transferred to the basal medium containing $20 \mathrm{mmol} / \mathrm{L}$ glucose in the absence (open bars) or presence (grey bars) of insulin for $24 \mathrm{~h}$. Treated cells means the adipocytes were treated with $10 \mu \mathrm{mol} / \mathrm{L}$ fatostatin concomitant with insulin treatment for $24 \mathrm{~h}$. Untreated cells means the cells were not treated by fatostatin. A: Quantification of lipogenesis in differentiated adipocytes by Oil Red O extraction. B-E: The relative mRNA level of $L X R \alpha(B)$, ChREBP (C), FAS (D) and ACC1 (E) measured by using real-time RT-PCR. * $(P<0.05)$ and ${ }^{* *}(P<0.01)$ mean the significant between treatments in the same cell group. \# $(P<0.05)$ and \#\# $(P<0.01)$ mean the significant between the same treatment in different cell groups. Data are means $\pm \mathrm{SEM}$.

A

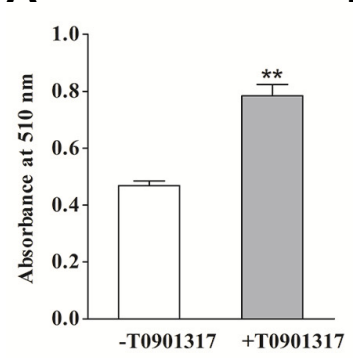

B

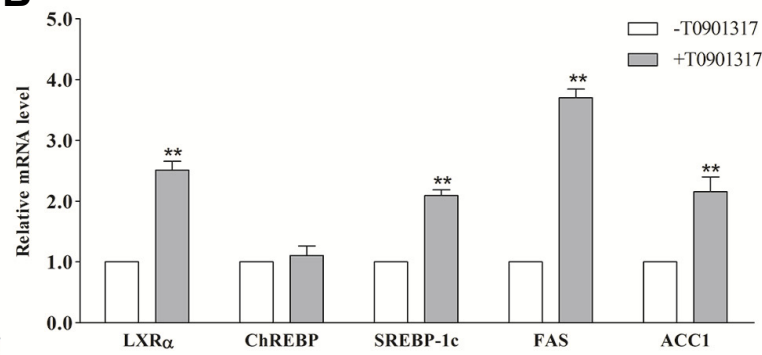

Fig. 5. The effect of $L X R \alpha$ activation on lipogenesis and relative genes expression. Differentiated adipocytes were shifted to the basal medium containing $20 \mathrm{mmol} / \mathrm{L}$ glucose with (grey bars) or without (open bars) $1 \mu \mathrm{mol} / \mathrm{L}$ LXR $\alpha$ agonist T0901317. After $24 \mathrm{~h}$, the cellular lipid content was analyzed by Oil Red $O$ extraction (A) and total RNA from triplicate plates of adipocytes was extracted and analyzed for relative genes by using real-time RTPCR (B). * $(P<0.05)$ and ${ }^{* *}(P<0.01)$ mean the significant between treatments. Data are means \pm SEM. creased the expression of SREBP-1c, but had no effect on ChREBP (Fig. 5B). Moreover, silencing of ChREBP expression or blocking of SREBP-1c activation had no effect on the upregulation of $L X R \alpha$ expression induced by T0901317 (Fig. 6B). In accordance with the effects on lipogenesis, T0901317 induced a stimulatory effect on FAS and ACC1 mRNA expressions $(P<$ 0.01 ) in differentiated adipocytes (Fig. 5B). Similarly, treating ChREBP-siRNA adipocytes with T0901317 resulted in upregulation of FAS $(P<0.01)$ and ACC1 expression $(P<0.05)$. However, in SREBP-1c blocked adipocytes, T0901317 treatment led only to a modest increase in FAS mRNA expression $(P<$ $0.05)$ rather than the mRNA expression of ACC1 $(P>0.05)$ (Figs. $6 C$ and $6 D$ ). These results indicate that $L X R \alpha$ may mediate the lipogenesis through SREBP-1c rather than ChREBP.

\section{LXR $\propto$ mediated the lipogenesis induced by glucose and by} insulin

To further study the role of $L X R \alpha$ in lipogenesis induced by glucose or insulin in porcine differentiated adipocyte, ChREBPsiRNA adipocytes treated with SREBP-1c inhibitor fatostatin (siRNA/FT) were exposed to $1 \mu \mathrm{mol} / \mathrm{L}$ T0901317 in the absence or presence of $20 \mathrm{mmol} / \mathrm{L}$ glucose or $200 \mathrm{nmol} / \mathrm{L}$ insulin for $24 \mathrm{~h}$, and then the cellular lipid content and the lipogenic genes expression were analyzed.

In the absence of glucose, activation of LXR $\alpha$ had no effect on lipogenesis and lipogenic gene expression (FAS and ACC1) both in unperturbed adipocytes (means "Control" in Figs. 7 and 8 ) and siRNA/FT adipocytes $(P>0.05)$. Addition of glucose promoted lipogenesis not only in unperturbed cells $(P<0.01)$ but also in siRNA/FT adipocytes $(P<0.05)$. In the presence of glucose, activation of $L X R \alpha$ resulted in a significant increase lipogenesis in siRNA/FT adipocytes $(P<0.05)$, whereas glucose only led to an increase tendency in unperturbed cells $(P>$ 0.05) (Fig. 7A). Consistent with the lipogenesis, the lipogenic gene expression (FAS and ACC1) also increased in the unperturbed cell response to T0901317 treatment. In siRNA/FT adi- 

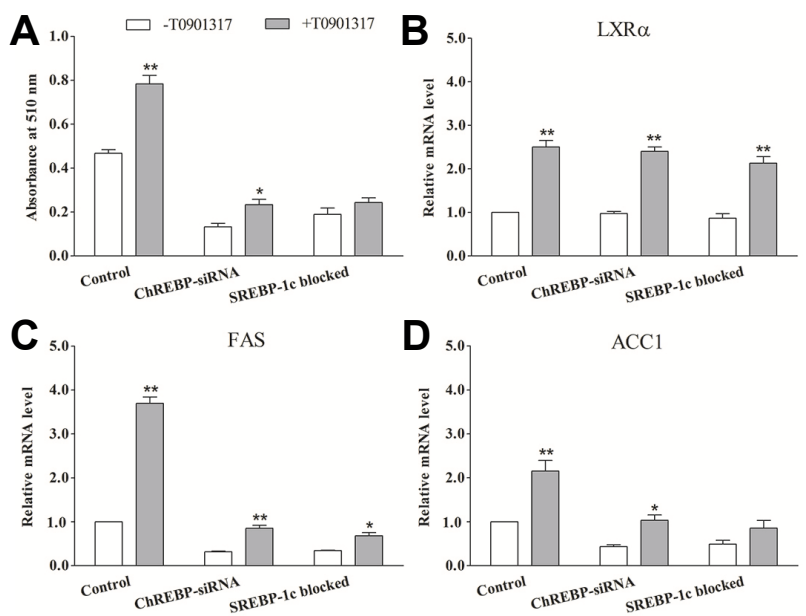

Fig. 6. The effect of activation of $L X R \alpha$ on lipogenesis and gene expression. Differentiated adipocytes were shifted to the basal medium containing $20 \mathrm{mmol} / \mathrm{L}$ glucose with (grey bars) or without (open bars) $1 \mu \mathrm{mol} / \mathrm{L} \mathrm{LXR} \alpha$ agonist T0901317. After $24 \mathrm{~h}$, the cellular lipid content was analyzed by Oil Red $\mathrm{O}$ extraction $(\mathrm{A})$ and total RNA from triplicate plates of adipocytes was extracted and analyzed for $L X R \alpha(B), F A S(C)$ and ACC1 (D) by using real-time RTPCR. ChREBP-siRNA means the ChREBP expression was interfered by transfecting with pcDNA6.2-GW/ EmGFP-ChREBP siRNA expression plasmid. SREBP-1c blocked means the adipocytes were treated with a combination of $10 \mu \mathrm{mol} / \mathrm{L}$ fatostatin and T0901317. Control indicates the unperturbed adipocytes. * $(P<$ $0.05)$ and ${ }^{* *}(P<0.01)$ mean the significant between treatments in the same cell group. Data are means \pm SEM.

pocytes, activation of $\mathrm{LXR} \alpha$ significantly facilitated FAS expression $(P<0.01)$ (Fig. 7B), while no significant changes were observed in ACC1 expression in siRNA/FT adipocytes in the context of glucose-stimulation (Fig. 7C). These results suggest that the lipogenesis promoted by $L X R \alpha$ activation is dependent on glucose, and glucose-induced lipogenesis could be mediated directly by LXR $\alpha$.

In $20 \mathrm{mmol} / \mathrm{L}$ glucose condition, insulin induced a stimulatory lipogenic response and induced gene expression of FAS and ACC1 $(P<0.01)$, and activation of LXR $\alpha$ intensified this effect in unperturbed cells (Fig. 8). Furthermore, LXR $\alpha$ activation promoted the lipogenesis and the expression of FAS and ACC1 independently of insulin. Treatment of siRNA/FT adipocytes with insulin or T0901317 alone resulted in an increase in the lipogenesis (Fig. 8A). The mRNA expression of FAS markedly increased in siRNA/FT adipocytes response to insulin or T0901317 alone $(P<0.05)$ (Fig. 8B). Simultaneous addition of T0901317 and insulin led to an increase of the ACC1 mRNA expression $(P<0.05)$ (Fig. $8 \mathrm{C})$. These results demonstrate that $\mathrm{LXR} \alpha$ could mediate the lipogenic-response induced by insulin by regulating the lipogenic gene expression patterns.

\section{DISCUSSION}

Mammals adapt to fluctuation of nutrient availability by storing surplus nutrient mainly in adipose tissue, in the form of triglyceride (TG). Upon consumption of excess carbohydrate, digestion yields glucose which is subsequently converted to pyruvate (glycolysis), and is either oxidized to provide energy or channeled into pathways for synthesis of fatty acids (lipogenesis) when energy is available. Lipogenesis is a process regulated by nutritional and hormonal control. Pig adipose tissue is the main lipogenesis organ (Bergen et al., 2005) and has a greater contribution to overall lipogenesis than does the liver (O'Hea and Leveille, 1969). Studies in hepatocytes and rodents adipocytes during the last decades have shown that ChREBP and SREBP-1c are key transcription factors in regulating the expression of the lipogenic genes in response to glucose and insulin, respectively (Uyeda and Repa, 2006; Xu et al., 2013), while $\mathrm{LXR} \alpha$ might be play a central for the transcriptional control ChREBP by glucose (Cha and Repa, 2007; Mitro et al., 2007) and SREBP-1c by insulin (Chen et al., 2004; Schultz et al., 2000).

Many researches in rodent models and human cell line studies have indicated that ChREBP is a glucose-responsive transcription factor that plays a critical role in converting excess carbohydrates to TG through de novo lipogenesis (Herman et al., 2012; Uyeda and Repa, 2006; Yamashita et al., 2001). However, the role of ChREBP in lipogenesis induced by glucose and insulin remains unclear in porcine adipocytes. Therefore, the primary porcine adipocytes were used to study the role of ChREBP in lipogenesis induced by glucose. Glucose significantly promoted the expression of ChREBP and was accompanied by increased lipogenesis and lipogenic genes FAS and ACC1 mRNA expression in porcine differentiated adipocytes.
A

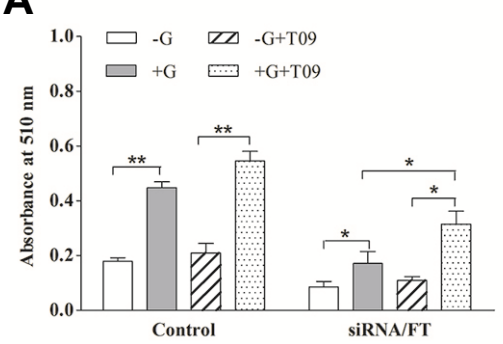

B

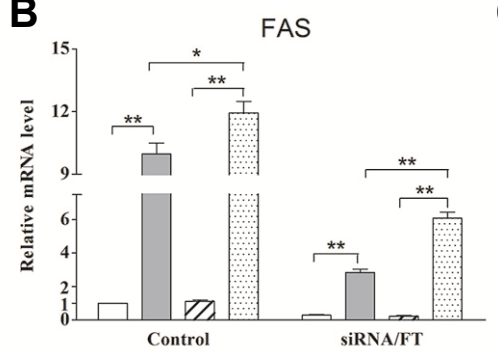

C

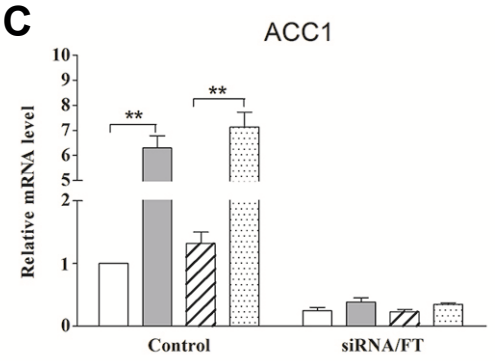

Fig. 7. The role of $L X R \alpha$ in lipogenesis induced by glucose in porcine differentiated adipocytes. The ChREBP-siRNA adipocytes were shifted to a glucose-free medium for $12 \mathrm{~h}$, and transferred to the basal medium with or without $1 \mu \mathrm{mol} / \mathrm{L}$ T0901317 in the absence or presence of 20 $\mathrm{mmol} / \mathrm{L}$ glucose. After $20 \mathrm{~h}$, the lipogenesis and the mRNA levels of these genes were measured. siRNA/FT means the adipocytes transfected with pcDNA6.2-GW/EmGFP-ChREBP siRNA expression plasmid were treated with a combination of SREBP-1c inhibitor fatostatin (10 $\mu \mathrm{mol} / \mathrm{L}$ ) and T0901317. Control indicates the unperturbed adipocytes. (A) Quantification of the cellular lipid content in differentiated adipocytes by Oil Red O extraction. (B, C) The relative mRNA level of FAS (B) and ACC1 (C) measured by using real-time RT-PCR. Data are means \pm SEM. 

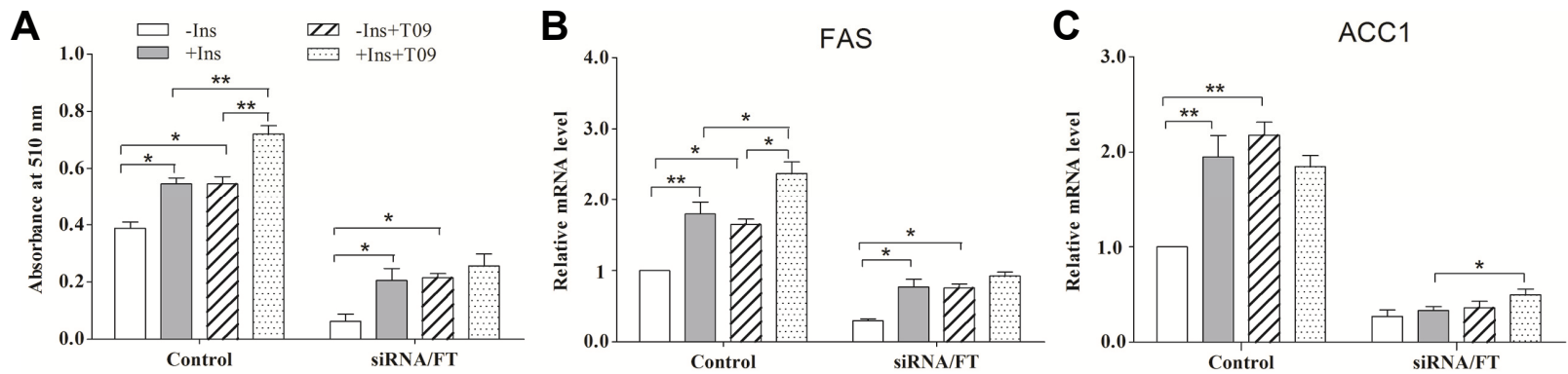

Fig. 8. The role of $L X R \alpha$ in lipogenesis induced by insulin in porcine differentiated adipocytes. The ChREBP-siRNA adipocytes were shifted to a serum-free medium for $12 \mathrm{~h}$, and transferred to the basal medium containing $20 \mathrm{mmol} / \mathrm{L}$ glucose with or without $1 \mu \mathrm{mol} / \mathrm{L}$ T0901317 in the absence or presence of $200 \mathrm{nmol} / \mathrm{L}$ insulin. After $24 \mathrm{~h}$, the lipogenesis and the mRNA levels of these genes were measured. siRNA/FT means the adipocytes transfected with pcDNA6.2-GW/EmGFP- ChREBP siRNA expression plasmid were treated with a combination of the SREBP1c inhibitor fatostatin $(10 \mu \mathrm{mol} / \mathrm{L})$ and T0901317. (A) Quantification of the cellular lipid content in differentiated adipocytes by Oil Red O extraction. $(B, C)$ The relative mRNA level of FAS $(B)$ and $A C C 1(C)$ measured by using real-time RT-PCR. Data are means $\pm S E M$.

These results are consistent with previous reports. Specifically, Denechaud et al. (2008) found that ACC1 and FAS expressions are regulated by glucose via ChREBP in mouse liver and white adipose tissue, and ChREBP activity and expression is induced by the consumption of a high-carbohydrate diet (Yamashita et al., 2001) and glucose (Herman et al., 2012), and then increase the activities of lipogenic enzymes (Aguiari et al., 2008; Uyeda and Repa, 2006; Uyeda et al., 2006). When ChREBP gene expression was silenced via siRNA, glucoseinduced lipogenesis decreased by $\sim 70 \%$ compared to the unperturbed cell. This suggests that glucose-induced lipogenesis mediates its effects mainly through ChREBP in porcine differentiated adipocytes. However, lipogenesis was still increased in ChREBP-silenced adipocytes treated with high concentration of glucose, indicating that the lipogenesis induced by glucose could be mediated through other transcription factors besides ChREBP in porcine differentiated adipocytes.

SREBP-1c is considered to be a master transcriptional regulator of fatty acid and TG synthesis in liver response to insulin stimulation (Hegarty et al., 2005; Ito et al., 2013; Lay et al., 2002). Despite significant improvements in our understanding of the role of SREBP-1c in the liver recent years, its role in adipose tissue remains largely unexplored. A previous study using cultured porcine adipocytes found the regulation of lipogenesis by insulin does not involve changes in SREBP-1c mRNA levels (Louveau and Gondret, 2004). However, the other study suggested that SREBP-1c is regulated by insulin and mediates insulin-induced fatty acid synthesis in human adipocytes (Ito et al., 2013). In the present study, our results demonstrated that insulin could promote the SREBP-1c mRNA level in porcine mature adipocytes. However, the increase in lipogenesis stimulated by insulin occurs in a glucose-dependent manner. These results are in accordance with research by Foufelle et al. (1992) which found glucose alone stimulates the expression of FAS and ACC in adipose tissue, but in the absence of glucose, insulin has no effect on lipogenic gene expression. Insulin potentiates the effect of glucose and simultaneously increases the concentration of glucose 6-phosphate. Glucose 6-phosphate is believed to be essential for both ChREBP nuclear translocation and transcriptional activity in response to glucose (Dentin et al., 2012; Li et al., 2010). He et al. (2004) found in the 3T3 adipocytes, ChREBP gene is also responsive to insulin stimulation, but that the induction is dependent on the presence of high glucose. In this context, we found that when SREBP-1c activa- tion was blocked, lipogenesis promoted by insulin was decreased by $\sim 55 \%$ in differentiated adipocytes. This suggests that lipogenesis induced by insulin was mediated by SREBP-1c in porcine differentiated adipocytes. When SREBP-1c activation was blocked by fatostatin, the addition of insulin still led to a significant increase in lipogenesis. This suggests there might be other transcription factors mediate the lipogenesis induced by insulin besides SREBP-1c in porcine differentiated adipocytes.

The work presented herein demonstrated that glucose could up-regulate the expression of $\mathrm{LXR} \alpha$ and SREBP-1c. Moreover, $\mathrm{LXR} \alpha$ activation could stimulate lipogenesis and induce mRNA expression of SREBP-1c and lipogenic gene (FAS and ACC1). Some previous studies have shown that nuclear receptor LXRs is a glucose sensor and the physiological concentrations of glucose can activate LXRs in the liver and induce expression of LXR target genes (Mitro et al., 2007). LXR $\alpha$ agonist treatment of adipocytes leads to the increased lipid accumulation (Juvet et al., 2003; Laffitte et al., 2003; Seo et al., 2004). SREBP-1c mRNA expression, on the other hand, is highly induced by ingestion of a high carbohydrate diet in liver (Horton et al., 1998) and by glucose in mesangial cells (Uttarwar et al., 2012). In the present study, activation of LXR $\alpha$ led to an increase in lipogenesis even in ChREBP-siRNA adipocytes. Furthermore, the magnitude of stimulation by LXR $\alpha$ agonist T0901317 in lipogenesis was in a very similar range in ChREBP-siRNA adipocytes and unperturbed cells. This suggests that ChREBP silencing does not attenuate the anxo-action in lipogenesis by T0901317. That is, $L X R \alpha$ may regulate lipogenesis but not via ChREBP in porcine differentiated adipocytes. Similarly, Denechaud et al. (2008) found that ChREBP expression is unaffected by the absence of LXR in mouse liver and white adipose tissue. Moreover, we found that siRNA-mediated ChREBP silencing had no effect on the up-regulation of $L X R \alpha$ mRNA expression induced by glucose and lipogenic gene expression were significantly increased when adipocytes were treated with T0901317. These results support the hypothesis that $L X R \alpha$ could directly, or via SREBP-1c, mediate glucose-induced lipogenesis through regulating the lipogenic genes expression. However, some other independent experiments in hepatocytes yielded conflicting results. The result by Cha and Repa (2007) raise the possibility that ChREBP is a target gene of LXR. The promoters of genes encoding ChREBP and SREBP-1c have LXR $\alpha$ binding sites and therefore ChREBP and SREBP-1c might be the target of LXR $\alpha$ (Mitro et al., 2007; Xu et al., 2013). Lipogenesis repre- 
sented by tissue and species specificity may explain these conflicting results. Herein we demonstrated that LXR $\alpha$ activation facilitate lipogenesis, expression of lipogenic genes and SREBP-1c expression in adipocytes. Glucose promoted lipogenesis in siRNA/FT adipocytes, even though the response was significantly lower than that observed in untreated adipocytes. When siRNA/FT adipocytes were treated by $L X R \alpha$ agonist, lipogenesis and FAS mRNA expression increased on basis of glucose. Thus, it might be concluded that $L X R \alpha$ may regulate lipogenesis induced by glucose through SREBP-1c.

In the present study, we found that insulin promoted LXR $\alpha$ expression in the presence of $20 \mathrm{mmol} / \mathrm{L}$ glucose. While $\mathrm{LXR} \alpha$ activation could up regulate SREBP-1c mRNA expression, it had little effect on lipogenesis when the activation of SREBP-1c was blocked by its inhibitor. These results indicate that $L X R \alpha$ may mediate lipogenesis via SREBP-1c. When ChREBPsilenced adipocytes were treated by both SREBP-1c inhibitor and $L X R \alpha$ agonist, the lipogenesis still significantly increased, suggesting $\mathrm{LXR} \alpha$ could directly mediate lipogenesis by regulating lipogenic gene expression. These results are supported by previous studies which have noted that LXRs could regulate FAS expression through direct interaction with the FAS promoter (Joseph et al., 2002; Shimano et al., 1999) and LXR $\alpha$ regulates ACC1 expression through activation of SREBP-1c expression (Horton et al., 2003). The facilitation effect of LXR agonists on genes involved in fatty acid synthesis has been suggested to be mediated both directly through LXR and via SREBP-1c (Joseph et al., 2002; Schultz et al., 2000). In brown adipocytes, the LXR agonist T0901317 increases the nuclear abundance of LXR and mature SREBP-1 (Jakobsson et al., 2005). The studies in cell culture and animal models suggest that the increase in plasma lipids occurs via LXR-mediated induction of the SREBP-1 lipogenic program (Schultz et al., 2000). In the present study, insulin did not lead to a significant increase in ChREBP expression both in the absence and presence of glucose. However, in human adipocytes, insulin promotes ChREBP expression (Hurtado del Pozo et al., 2011). ChREBP is also regulated by insulin in 3T3-L1 adipocytes and rat adipose tissue (He et al., 2004). Our study found that insulin still result in an increase in lipogenesis and expression of lipogenic genes when both of ChREBP expression was silenced and SREBP-1c activation was blocked simultaneously. This means $L X R \alpha$ directly mediate the lipogenesis induced by insulin in porcine adipocytes. The lipogenesis stimulated by insulin is dependent of high concentration of glucose in the medium. ChREBP mRNA expression might reach the maximal level in the high concentration of glucose, which may explain partly these inconsistent results.

Carbohydrate is a main energy resource from diet for pigs. After the animal intake carbohydrate, increased blood sugar stimulates secretion of insulin, which regulates transcription expression of genes involved in glucolysis and fatty acid synthesis. Glucose, which metabolites acts as a signaling molecule, regulates expression of genes responsive to glucose in an insulin-independent way. As above, glucose and insulin could stimulate lipogenesis through both dissimilar and identical pathways in porcine differentiated adipocytes. ChREBP and SREBP-1c are the key transcription factors in the lipogenesis response to glucose and insulin in porcine adipocytes, respectively. Lipogenesis facilitated by glucose was mainly mediated through ChREBP, and also through $L X R \alpha$ directly or via SREBP-1c, which regulated the expression of lipogenic genes such as FAS and ACC1. Insulin could promote the lipogenesis in a glucose-dependent fashion, and this induction be mainly mediated directly through SREBP-1c, and also through LXR $\alpha$ directly or via SREBP-1c regulating the lipogenic genes expression. As such, we suggest that $\mathrm{LXR} \alpha$ might play a central role in the transcriptional control by glucose and insulin in porcine differentiated adipocytes.

Note: Supplementary information is available on the Molecules and Cells website (www.molcells.org).

\section{ACKNOWLEDGEMENTS}

This work has been financial supported by the National Natural Science Foundation of China (No. 31460589 and 31560639) and by the Initial Founding of Scientific Research for the introduction of talents of Northwest University for Nationalities (No. xbmujrc201122) and by the Program for Changjiang Scholars and Innovative Research Team in University (IRT13091).

\section{REFERENCES}

Aguiari, P., Leo, S., Zavan, B., Vindigni, V., Rimessi, A., Bianchi, K., Franzin, C., Cortivo, R., Rossato, M., Vettor, R., et al. (2008). High glucose induces adipogenic differentiation of musclederived stem cells. Proc. Natl. Acad. Sci. USA 105, 1226-1231.

Bergen, W.G., and Mersmann, H.J. (2005). Comparative aspects of lipid metabolism: Impact on contemporary research and use of animal models. J. Nutr. 135, 2499-2502.

Cha, J.Y., and Repa, J.J. (2007). The liver x receptor (Ixr) and hepatic lipogenesis - the carbohydrate-response element-binding protein is a target gene of Ixr. J. Biol. Chem. 282, 743-751.

Chen, G., Liang, G., Ou, J., Goldstein, J.L., and Brown. M.S. (2004) Central role for liver $x$ receptor in insulin-mediated activation of srebp-1c transcription and stimulation of fatty acid synthesis in liver. Proc. Natl. Acad. Sci. USA 101, 11245-11250.

Chen, W., Chen, G., Head, D.L., Mangelsdorf, D.J., and Russell, D.W. (2007). Enzymatic reduction of oxysterols impairs Ixr signaling in cultured cells and the livers of mice. Cell Metab. 5, 73-79.

Denechaud, P.D., Bossard, P., Lobaccaro, J.M., Millatt, L., Staels, B., Girard, J., and Postic, C. (2008). Chrebp, but not Ixrs, is required for the induction of glucose-regulated genes in mouse liver. J. Clin. Invest. 118, 956-964.

Dentin, R., Girard, J., and Postic, C. (2005). Carbohydrate responsive element binding protein (chrebp) and sterol regulatory element binding protein-1c (srebp-1c): Two key regulators of glucose metabolism and lipid synthesis in liver. Biochimie 87, 8186.

Dentin, R., Tomas-Cobos, L., Foufelle, F., Leopold, J., Girard, J., Postic, C., and Ferre, P. (2012). Glucose 6-phosphate, rather than xylulose 5-phosphate, is required for the activation of chrebp in response to glucose in the liver. J. Hepatol. 56, 199-209.

Dodson, M.V., Hausman, G.J., Guan, L., Du, M., Rasmussen, T.P., Poulos, S.P., Mir, P., Bergen, W.G., Fernyhough, M.E., McFarland, D.C., et al. (2010). Lipid metabolism, adipocyte depot physiology and utilization of meat animals as experimental models for metabolic research. Int. J. Biol. Sci. 6, 691-699.

Foufelle, F., Gouhot, B., Pegorier, J.P., Perdereau, D., Girard, J., and Ferre, P. (1992). Glucose stimulation of lipogenic enzyme gene expression in cultured white adipose tissue. A role for glucose 6-phosphate. J. Biol. Chem. 267, 20543-20546.

He, Z., Jiang, T., Wang, Z., Levi, M., and Li. J. (2004). Modulation of carbohydrate response element-binding protein gene expression in 3t3-l1 adipocytes and rat adipose tissue. Am. J. Physiol. Endocrinol. Metab. 287, E424-430.

Hegarty, B.D., Bobard, A., Hainault, I., Ferre, P., Bossard, P., and Foufelle, F. (2005). Distinct roles of insulin and liver $x$ receptor in the induction and cleavage of sterol regulatory element-binding protein-1c. Proc. Natl. Acad. Sci. USA 102, 791-796.

Herman, M.A., Peroni, O.D., Villoria, J., Schon, M.R., Abumrad, N.A., Bluher, M., Klein, S., and Kahn, B.B. (2012). A novel chrebp isoform in adipose tissue regulates systemic glucose metabolism. Nature 484, 333-338.

Horton, J.D., Bashmakov, Y., Shimomura, I., and Shimano, H. 
(1998). Regulation of sterol regulatory element binding proteins in livers of fasted and refed mice. Proc. Natl. Acad. Sci. USA 95, 5987-5992.

Horton, J.D., Shah, N.A., Warrington, J.A., Anderson, N.N., Park, S.W., Brown, M.S., and Goldstein, J.L. (2003). Combined analysis of oligonucleotide microarray data from transgenic and knockout mice identifies direct srebp target genes. Proc. Natl. Acad. Sci. USA 100, 12027-12032.

Hurtado del Pozo, C., Vesperinas-García, G., Miguel-Ángel, R., Corripio-Sánchez, R., Torres-García, A.J., Obregon, M.J., and Calvo, R.M. (2011). Chrebp expression in the liver, adipose tissue and differentiated preadipocytes in human obesity. BBA Mol. Cell. Bio. L. 1811, 1194-1200.

Ito, M., Nagasawa, M., Omae, N., Tsunoda, M., Ishiyama, J., Ide, T., Akasaka, Y., and Murakami, K. (2013). A novel jnk2/srebp-1c pathway involved in insulin-induced fatty acid synthesis in human adipocytes. J. Lipid Res. 54, 1531-1540.

Jakobsson, A., Jorgensen, J.A., and Jacobsson. A. (2005). Differential regulation of fatty acid elongation enzymes in brown adipocytes implies a unique role for elovl3 during increased fatty acid oxidation. Am. J. Physiol. Endocrinol. Metab. 289, E517-526.

Janowski, B.A., Grogan, M.J., Jones, S.A., Wisely, G.B., Kliewer, S.A., Corey, E.J., and Mangelsdorf, D.J. (1999). Structural requirements of ligands for the oxysterol liver $\mathrm{x}$ receptors Ixralpha and Ixrbeta. Proc. Natl. Acad. Sci. USA 96, 266-271.

Joseph, S.B., Laffitte, B.A., Patel, P.H., Watson, M.A., Matsukuma, K.E., Walczak, R., Collins, J.L., Osborne, T.F., and Tontonoz, P. (2002). Direct and indirect mechanisms for regulation of fatty acid synthase gene expression by liver $x$ receptors. J. Biol. Chem. 277, 11019-11025.

Juvet, L.K., Andresen, S.M., Schuster, G.U., Dalen, K.T., Tobin, K.A., Hollung, K., Haugen, F., Jacinto, S., Ulven, S.M., Bamberg, K., et al. (2003). On the role of liver $x$ receptors in lipid accumulation in adipocytes. Mol. Endocrinol. 17, 172-182.

Kamisuki, S., Mao, Q., Abu-Elheiga, L., Gu, Z., Kugimiya, A., Kwon, Y., Shinohara, T., Kawazoe, Y., Sato, S., Asakura, K., et al. (2009). A small molecule that blocks fat synthesis by inhibiting the activation of srebp. Chem. Biol. 16, 882-892.

Korach-Andre, M., Archer, A., Barros, R.P., Parini, P., and Gustafsson, J.A. (2011). Both liver-x receptor (Ixr) isoforms control energy expenditure by regulating brown adipose tissue activity. Proc. Natl. Acad. Sci. USA 108, 403-408.

Laffitte, B.A., Chao, L.C., Li, J., Walczak, R., Hummasti, S., Joseph, S.B., Castrillo, A., Wilpitz, D.C., Mangelsdorf, D.J., Collins, J.L., et al. (2003). Activation of liver $x$ receptor improves glucose tolerance through coordinate regulation of glucose metabolism in liver and adipose tissue. Proc. Natl. Acad. Sci. USA 100, 54195424.

Lay, S.L., Lefrère, I., Trautwein, C., Dugail, I., and Krief. S. (2002). Insulin and sterol-regulatory element-binding protein-1c (srebp1c) regulation of gene expression in 3t3-l1 adipocytes: Identification of ccaat/enhancer-binding protein $\beta$ as an srebp-1c target. J. Biol. Chem. 277, 35625-35634.

Lehmann, J.M., Kliewer, S.A., Moore, L.B., Smith-Oliver, T.A., Oliver, B.B., Su, J.L., Sundseth, S.S., Winegar, D.A., Blanchard, D.E., Spencer, T.A., et al. (1997). Activation of the nuclear receptor Ixr by oxysterols defines a new hormone response pathway. J. Biol. Chem. 272, 3137-3140.

Li, M.V., Chen, W.Q., Harmancey, R.N., Nuotio-Antar, A.M., Imamura, M., and Saha, P. Taegtmeyer, H., Chan, L. (2010). Glucose-6-phosphate mediates activation of the carbohydrate responsive binding protein (chrebp). Bioche. Bioph. Res. Co. 395, 395-400.

Louveau, I., and Gondret. F. (2004). Gh and insulin affect fatty acid synthase activity in isolated porcine adipocytes in culture without any modifications of sterol regulatory element binding protein-1 expression. J. Endocrinol. 181, 271-280

Mitro, N., Mak, P.A., Vargas, L., Godio, C., Hampton, E., Molteni, V., Kreusch, A., and Saez, E. (2007). The nuclear receptor Ixr is a glucose sensor. Nature 445, 219-223.

O'Hea, E.K. and Leveille, G.A. (1969). Significance of adipose tissue and liver as sites of fatty acid synthesis in the pig and the efficiency of utilization of various substrates for lipogenesis. J. Nutr. 99, 338-344.

Ramírez-Zacarías, J.L., Castro-Muñozledo, F., and Kuri-Harcuch, W. (1992). Quantitation of adipose conversion and triglycerides by staining intracytoplasmic lipids with oil red $\mathrm{o}$. Histochem. Cell Biol. 97, 493-497.

Repa, J.J., Liang, G., Ou, J., Bashmakov, Y., Lobaccaro, J.M. Shimomura, I., Shan, B., Brown, M.S., Goldstein, J.L., and Mangelsdorf, D.J. (2000). Regulation of mouse sterol regulatory element-binding protein-1c gene (srebp-1c) by oxysterol receptors, Ixralpha and Ixrbeta. Genes Dev. 14, 2819-2830.

Schultz, J.R., Tu, H., Luk, A., Repa, J.J., Medina, J.C., Li, L., Schwendner, S., Wang, S., Thoolen, M., Mangelsdorf, D.J., et al. (2000). Role of Ixrs in control of lipogenesis. Genes Dev. 14, 2831-2838.

Seo, J.B., Moon, H.M., Kim, W.S., Lee, Y.S., Jeong, H.W., Yoo, E.J., Ham, J., Kang, H., Park, M.G., Steffensen, K.R., et al. (2004). Activated liver X receptors stimulate adipocyte differentiation through induction of peroxisome proliferatoractivated receptor gamma expression. Mol. Cell. Biol. 24, 34303444.

Shimano, H., Yahagi, N., Amemiya-Kudo, M., Hasty, A.H., Osuga, J., Tamura, Y., Shionoiri, F., lizuka, Y., Ohashi, K., Harada, K., et al. (1999). Sterol regulatory element-binding protein-1 as a key transcription factor for nutritional induction of lipogenic enzyme genes. J. Biol. Chem. 274, 35832-35839.

Uttarwar, L., Gao, B., Ingram, A.J., and Krepinsky, J.C. (2012). Srebp-1 activation by glucose mediates tgf-beta upregulation in mesangial cells. Am. J. Physiol. Renal. Physiol. 302, F329-341.

Uyeda, K., and Repa, J.J. (2006). Carbohydrate response element binding protein, chrebp, a transcription factor coupling hepatic glucose utilization and lipid synthesis. Cell Met. 4, 107-110.

Uyeda, K., Yamashita, H., and Kawaguchi, T. (2002). Carbohydrate responsive element-binding protein (chrebp): A key regulator of glucose metabolism and fat storage. Biochem. Pharmacol. 63912, 2075-2080.

Xu, X., So, J.S., Park, J.G., and Lee, A.H. (2013). Transcriptional control of hepatic lipid metabolism by srebp and chrebp. Semin. Liver Dis. 33, 301-311.

Yamashita, H., Takenoshita, M., Sakurai, M., Bruick, R.K., Henzel, W.J., Shillinglaw, W., Arnot, D., and Uyeda, K. (2001). A glucoseresponsive transcription factor that regulates carbohydrate metabolism in the liver. Proc. Natl. Acad. Sci. USA 98, 91169121.

Yaqiu, L., Helin. Z., and Gongshe, Y. (2007). Effects of RXR $\alpha$ gene silencing on the porcine adipocyte differentiation on vitro. Comp. Biochem. Physi. D. 2, 207-214.

Zanotti, I., Poti, F., Pedrelli, M., Favari, E., Moleri, E., Franceschini, G., Calabresi, L., and Bernini, F. (2008). The Ixr agonist t0901317 promotes the reverse cholesterol transport from macrophages by increasing plasma efflux potential. J. Lipid Res. 49, 954-960.

Zhang, G.H., Lu, J.X., Chen, Y., Zhao, Y.Q., Guo, P.H., Yang, J.T., and Zang, R.X. (2014). Comparison of the adipogenesis in intramuscular and subcutaneous adipocytes from bamei and landrace pigs. Biochem. Cell Biol. 92, 259-267.

Zhang, G.H., Lu, J.X., Chen, Y., Guo, P.H., Qiao, Z.L., Feng, R.F., Chen, S.E., Bai, J.L., Huo, S.D., and Ma, Z.R. (2015). Chrebp and Ixralpha mediate synergistically lipogenesis induced by glucose in porcine adipocytes. Gene 565, 30-38. 